\title{
Estimation of carbon sink in surface carbonate rocks of Guangxi Province by using remote sensing images
}

\author{
Bin Jia ${ }^{1}$, Guoqing Zhou ${ }^{1}{ }^{*}$, Haoyu Wang ${ }^{1}$, Tao Yue ${ }^{1}$, Wei Huang ${ }^{1,2}$ \\ ${ }^{1}$ Guangxi Key Laboratory of Spatial Information and Geomatics, Guilin University of Technology, Guilin, 541004, China - \\ gzhou@glut.edu.cn \\ ${ }^{2}$ Department of Mechanical and Control Engineering, Guilin University of Technology, Guilin, 541004, China - \\ 102016477@glut.edu.cn
}

Commission III, WG III/8

KEY WORDS: Dissolution test method, Carbonate rocks, Miss carbon sink, ArcGIS

\begin{abstract}
:
Studies of the imbalance of source sinks in the carbon cycle show that $\mathrm{CO}_{2}$ absorbed during rock weathering is part of the "miss carbon" of the global carbon cycle. The carbon sink contribution of carbonate rocks obviously plays a very important role in the absorption of atmospheric $\mathrm{CO}_{2}$. Estimation of carbon sinks in karst dynamic system of Guangxi province has great significance for further understanding of global karst carbon cycle and global climate research. This paper quotes the rock data from Tao Xiaodong's paper, which is obtained using RS and GIS techniques. At the same time, the dissolution rate model studied by Zhou Guoqing and others was used to estimate the dissolution rate of carbonate rocks in Guangxi Province. Finally, the $\mathrm{CO}_{2}$ content consumed by carbonate karstification in Guangxi Province was $1342910.447 \mathrm{ta}^{-1}$. The results obtained are in the same order of magnitude as the $\mathrm{CO}_{2}$ content consumed by carbonate rock karstification in Guangxi Province calculated by Tao Xiaodong.
\end{abstract}

\section{INTRODUCTION}

The discussion of the relationship between global climate change and the increase of atmospheric greenhouse gas concentration has caused public concern about the earth's carbon cycle (Yuan, 2011). The greenhouse gases that cause global climate change are an important part of the global carbon cycle. Studies of the imbalance of source sinks in the carbon cycle show that $\mathrm{CO}_{2}$ absorbed during rock weathering is part of the "miss carbon" in the global carbon cycle. Siegenthaler et al. (1993) found that $1.8 \mathrm{PgC}$ was an undetected residue of terrestrial carbon sinks, which is called "miss carbon sinks" $(\mathrm{Qu}$ et al., 2004). It is generally assumed that this unknown carbon sink may have terrestrial vegetation or soil (Pan et al., 2011; Friedlingstein et al., 1995). The amount of carbon in carbonate rocks stored in the lithosphere is more than $6.0 \times 108$ million tons, 1562 times and $3.0 \times 104$ times that of marine and terrestrial vegetation respectively (Falkowski et al., 2000). The carbonate rocks stored in the lithosphere are rarely considered. The role of the lithosphere in atmospheric carbon dioxide is listed as a long-term cycle, while ignoring the carbon dioxide absorption and dynamic changes in the lithosphere. Therefore, carbonate karstification can be used to study this unknown carbon sink. Because they consume carbon in the atmosphere or soil (Gombert, 2002).

The relationship between carbon sink and the source sink of atmosphere was analyzed by means of the dissolution test method, dynamic method, hydrochemical methods and model establishment. Internationally, Ichikuni (1976), Kitano (1984), Inokura (1997), Yuan (1997), Ludwig (1998), Liu (2000), Gombert (2002) and other researchers have calculated the carbon of rock weathering consumption, indicating that the contribution of carbonate sinks is greater than that of source. The contribution of carbon sinks to carbonates rocks Karstification obviously plays a very important role in the absorption of atmospheric $\mathrm{CO}_{2}$. Therefore, it is of great research significance to estimate the exploration of the global carbon cycle and the study of global climate by the carbon sink of karst dynamic system.

China has a large number of karst landform areas, while Guangxi Province is one of the more abundant karst provinces in China. The Karst effect is very strong because of the abundant rainfall and mild climate. In this paper, Guangxi province is selected as the research area, and the rock data (Tao, 2013) of Tao Xiaodong's paper is cited, which are abtained by RS and GIS technologies. At the same time, the dissolution rate model studied by Zhou et al. (2017) was used to estimate the dissolution rate in Guangxi. Finally, the carbon sink of surface karstification in the karst area of Guangxi Province was estimated from the rock data and dissolution rate.

\section{EXPERIMENTAL DATA}

\subsection{Rock Data}

The area of carbonate rocks in Guangxi Province comes from the master's thesis of Tao Xiaodong. The data acquisition of rock area is based on the sixth band of the original TM remote sensing image in Guangxi area as the original data (Figure 1), and the Landsat TM6 is divided into 7 categories by supervised classification. Classification results shown in Figure 2. Using remote sensing technology can get some effects on lithology extraction, but the classification accuracy is not high, so Tao Xiaodong uses recalciton lithology based on ArcGIS geological map and figure 2(Tao, 2013). 


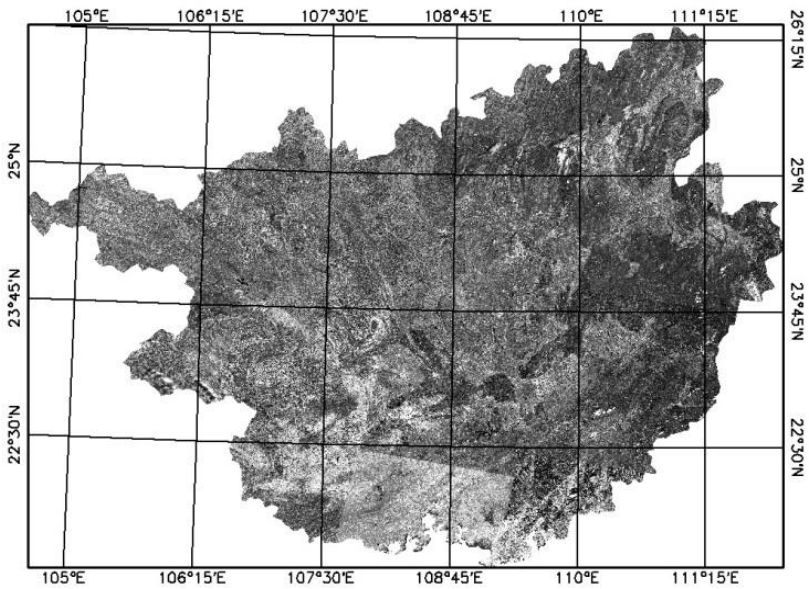

Figure 1. Original TM Remote Sensing Image in Guangxi (Tao, 2013)

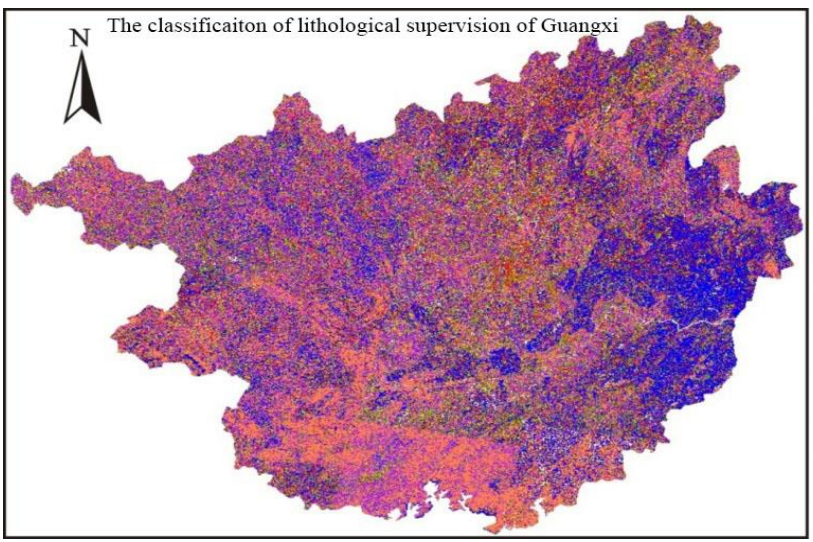

Figure 2. Classification of lithological supervision (Tao, 2013)

\subsection{Rainfall Data and Temperature Data}

The rainfall data and temperature data calculated in this paper are from the national meteorological data sharing service platform and the data website is data.cma.cn. The rainfall and temperature data are for the 24 meteorological stations in Guangxi in 2010 (Figure 3). We use the common Kriging method in ArcGIS to predict the surface temperature and rainfall data of 24 meteorological stations in Guangxi in 2010 and generalize the point data to surface data. The results are shown in Figure 4 and Figure 5.

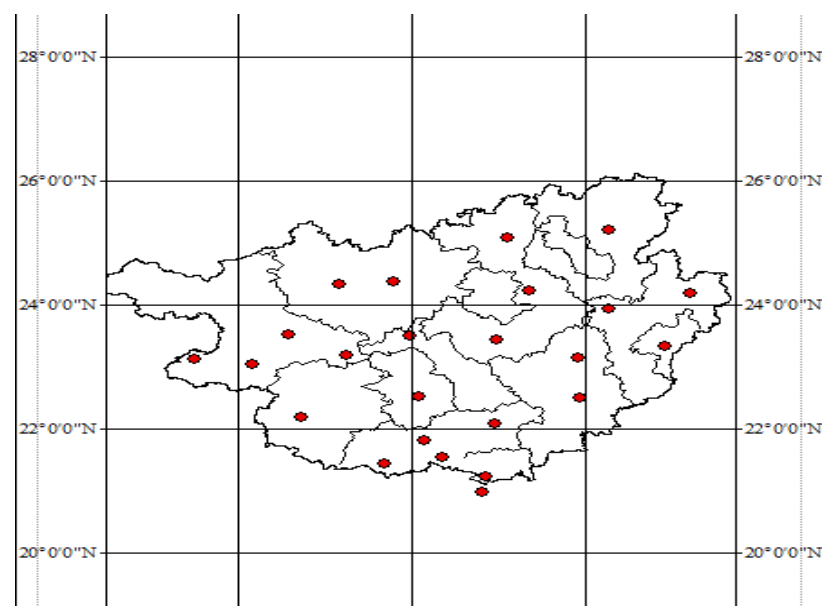

Figure 3. 24 meteorological stations in Guangxi Province

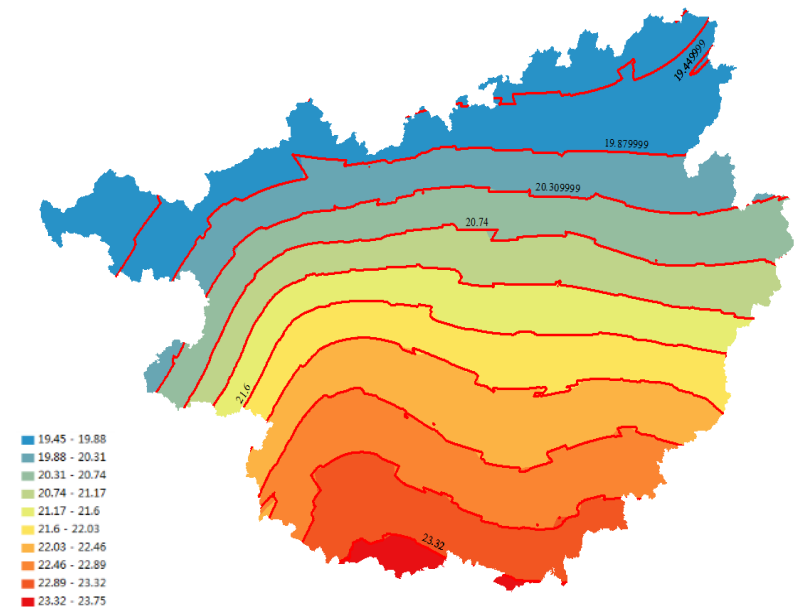

Figure 4. Distribution of temperature data in Guangxi Province

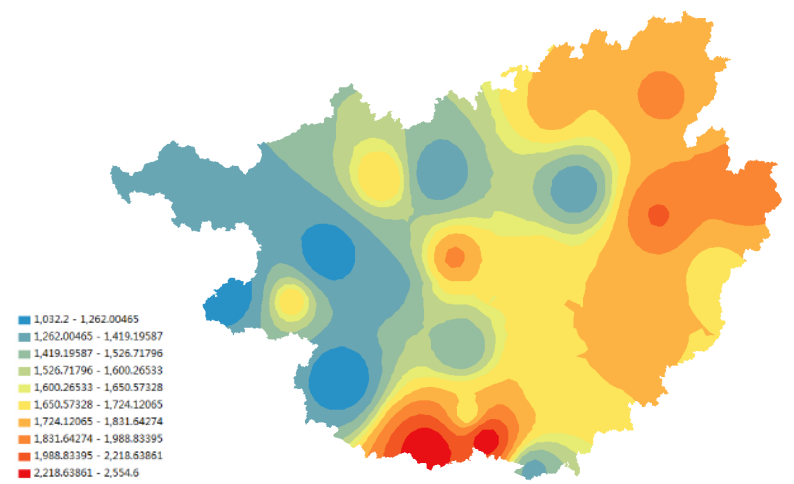

Figure 5. Distribution map of rainfall in Guangxi Province

\section{RESEARCH METHODS AND ESTIMATION OF KARST CARBON SINK IN GUANGXI PROVINCE}

\subsection{Karst Carbon Sink Research Methods}

Because karst dynamic system is an open system, there is great difficulty in studying the carbon sink produced by karstification. Researchers often use the following methods to study the karstification of rocks: dynamic method, hydrochemical methods, dissolution test method.

3.1.1 Dynamic method: dynamic method is a method of calculating the reaction rate based on the reactant or product concentration relationship. It is an effective method for analyzing the rate mechanism and reaction mechanism of karstification under experimental conditions and is suitable for karst microscopic studies. Dynamic method is representative of PWP model (Plummer et al., 1978) and DBL model (Dreybrodt et al., 1991). In 2000, Liu Zahua (2000) and others used dynamic method to estimate the karst carbon sink and global karst carbon sink in China.

3.1.2 Hydrochemical methods: The hydrochemical method is considered that runoff is the factor that influences the weathering rate of rocks. The relationship between rock weathering rate and runoff of different types of rocks is analyzed. And the consumption of $\mathrm{CO}_{2}$ in large scale karst process is estimated. Typical hydrochemical methods include the GEM- $\mathrm{CO}_{2}$ Model (Amiotte et al., 1995) and the SiB algorithm (Pacheco et al., 1996). 
3.1.3 Dissolution test method: Dissolution test strip method is a field experiment method. In the field experiment, the geographical location and environment of the experimentation area should be taken into consideration. In the surface karst dynamic system, the rock has a sink effect with atmospheric $\mathrm{CO}_{2}$, and the estimation of karstic carbon sink mainly consists of the dissolution equation of limestone:

$$
\mathrm{CaCO}_{3}+\mathrm{CO}_{2}+\mathrm{H}_{2} \mathrm{O} \Leftrightarrow \mathrm{Ca}^{2+}+2 \mathrm{HCO}_{3}^{-}
$$

Therefore, the formula for calculating atmospheric $\mathrm{CO}_{2}$ sinks is as follows:

$$
\mathrm{F}=\mathrm{E} \times \mathrm{S} \times \mathrm{R} \times \mathrm{M}_{\mathrm{CO}_{2}} / \mathrm{M}_{\mathrm{CaCO}_{3}}
$$

Where $\mathrm{F}$ is the sink of $\mathrm{CO}_{2}$ at $10^{10} \mathrm{~g} \cdot \mathrm{a}-1 ; \mathrm{S}$ is the karst area at $\mathrm{km}^{2} ; \mathrm{R}$ is the carbonate rock purity of rock specimen at $\mathrm{R}=0.97$; $\mathrm{E}$ is the corrosion rate of the rock specimen at $\mathrm{mgcm}^{-2} \mathrm{a}^{-1} ; \mathrm{M}_{\mathrm{CO}_{2}}$ is the molecular weight of at $\mathrm{M}_{\mathrm{CO}_{2}}=44 ; \mathrm{M}_{\mathrm{CaCO}_{3}}$ is the molecular weight of $\mathrm{M}_{\mathrm{CaCO}_{3}}$, usually, $\mathrm{M}_{\mathrm{CaCO}_{3}}=100$.

In the study of rock weathering in Guangxi Province, rock carbon sinks are calculated by formula (2). The dissolution rate model fitted by Zhou Guoqing et al based on the data of 18 corrosion test sites in China (using the dissolution test method). The karst carbon sink in Guangxi province is calculated according to the dissolution rate model.

\subsection{Estimate of Guangxi Karst Carbon Sink}

According to the dissolution rate model fitted by Zhou Guoqing et al., it is found that temperature and rainfall are the influence factors of the dissolution rate. The temperature data and rainfall data of 24 meteorological stations in Guangxi Province were predicted by using the Kriging method in ArcGIS in 2010 (Figure 4 and Figure 5). The dissolution rate of carbonate rocks in Guangxi Province is determined by combining the rock classification maps of Guangxi in Figure 6. The carbon sink of carbonate rocks karstification in Guangxi Province are calculated based on the rock area data in Table 1 .

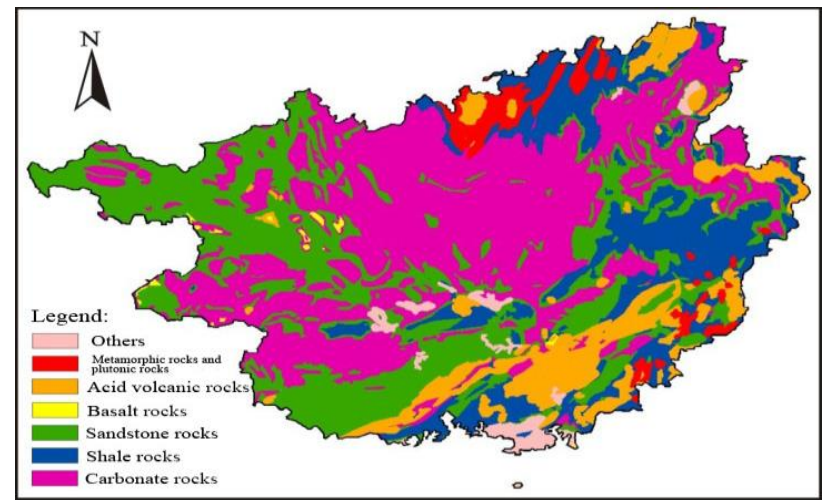

Figure 5. The classification result of lithology in Guangxi (Tao, 2013)

\begin{tabular}{cc}
\hline Rock types & Size of area $\left(\mathrm{km}^{2}\right)$ \\
\hline Metamorphic rocks and & 3691.35 \\
plutonic rocks & 19669.10 \\
Acid volcanic rocks & 874.42 \\
Basalt & 72275.76 \\
Sandstone & \\
\hline
\end{tabular}

\begin{tabular}{cc}
\hline Shale rocks & 37756.96 \\
Carbonate rocks & 99599.16 \\
\hline
\end{tabular}

Table 1. Area Data for Different Rock Types in Guangxi Province (Tao, 2013)

In Figure 5, in addition to carbonate rocks, the remaining five types of rocks are metamorphic and plutonic, acidic volcanic rocks, basalts, sand and sandstone, and shales belong to silicate rocks (Tao, 2013). Because of the solubility of silicate minerals and slow weathering kinetics, it is more than one order of magnitude lower than that of carbonate (Amiotte et al., 1995; Pacheco et al., 1996; Ludwig et al., 1998; Roy et al., 1999; Mortatti et al., 2003; Wu et al., 2008). Therefore, this paper mainly estimates the $\mathrm{CO}_{2}$ content absorbed by carbonate karstification in Guangxi Province. The dissolution rate model studied by Zhou et al. (2017) is as follows:

$$
\begin{aligned}
& E=5.322-0.9609 \times T+0.00533 \times P \\
& +0.0627 \times T^{2}-0.001133 \times T \times P \\
& +0.000007675 \times P^{2}
\end{aligned}
$$

Based on the temperature data and rainfall data (Figures 4 and 5), the dissolution rate of carbonate rocks in Guangxi is calculated by formula (3). Using Equation 2, the $\mathrm{CO}_{2}$ content consumed by carbonate karstification in Guangxi Province is $1342910.447 \mathrm{t} \cdot \mathrm{a}^{-1}\left(366248.3037 \mathrm{Ct} \cdot \mathrm{a}^{-1}\right)$.

\section{CONCLUNSIONS}

According to the influence factors of the fitted dissolution rate model, the rainfall rate and temperature data were selected to calculate the dissolution rate of carbonate rocks in Guangxi Province, which was $3.16 \mathrm{mg} \cdot \mathrm{cm}^{-2} \mathrm{a}^{-1}$. Finally, the $\mathrm{CO}_{2}$ content consumed by carbonate karstification in Guangxi Province is $1342910.447 \mathrm{t} \cdot \mathrm{a}^{-1}$. The obtained results are in the same order of magnitude as the $\mathrm{CO}_{2}$ content consumed by carbonate rock karstification in Guangxi Province calculated by Tao Xiaodong, indicating that this result is still credible.

\section{ACKNOWLEDGEMENTS}

This paper is financially supported by the National Key Research and Development Program of China under Grant numbers 2016YFB0502500, the National Natural Science of China under Grant numbers 41431179, the State Oceanic Administration under Grant numbers 2014\#58, Kangxi Natural Science Foundation under grant numbers 2015GXNSFDA139032, Guangxi Science \& Technology Development Program under the Contract number GuiKeHe 14123001-4, Kangxi Key Laboratory of Spatial Information and Geomatics Program under Grant numbers 151400701, 151400712 and 163802512, Guangxi doctoral student innovation under grant numbers YCBZ2018054, Kangxi Key Laboratory of Spatial Information and Geomatics Program under grant numbers 151400734 and 163802518 .

\section{REFERENCES}

Yuan. D. X., 2011. Foreword for the special topic "Geological Processes in Carbon Cycle". Chinese Science Bulletin, 56(35), pp. 3741-3742.

Siegenthaler, U. and Sarmiento, J. L., 1993. Atmospheric carbon dioxide and the ocean. Nature, 365 (6442), pp. 119-125. 
Qu, D. S., Zhuang, D. F. and Hu, Y. F., 2004. Estimation of carbon sink capacity due to weathering of Chinese rocks. Earth Science-Journal of China University of Geosciences, 29 (2), pp. 177-182.

Pan, Y., Birdsey, R. A., Fang, J., et al., 2011. A large and persistent carbon sink in the world's forests. Science, 333(6045), pp. 988-993.

Friedlingstein, P., Fung, I., Holland, E., et al., 1995. On the contri- bution of $\mathrm{CO}_{2}$ fertilization to the missing biospheric sink Global Biogeochemical Cycles, 9(4), pp. 541-556.

Falkowski, P., Scholes, R. J., et al., 2000. The global carbon cycle: A test of our knowledge of earth as a system. Science, 290, pp. 291-296.

Gombert, P., 2002. Role of karstic dissolution in global carbon cycle. Global \& Planetary Change, 33(1), pp. 177-184.

Ichikuni, M., 1976. Role of water in geochemical systems. Ions and solvents. Tokyo University Publishers, Tokyo.

Kitano, Y., 1984. Environmental chemistry of the earth. Shokabo, Tokyo.

Inokura, Y., 1997. The geochemical cycle of carbon dioxide in a carbonate rock area, Akiyoshi-dai Plateau, Yamaguchi, Southwestern Japan. Proc. 30th. Int. Geol. VSP, Utrecht, the Netherlands, 24, pp. 114-126.

Yuan, D. X., 1997. The carbon cycle in karst. Zeitschrift Fur Geomorphologie Supplementband, pp. 91-102.

Ludwig, W. et al., 1998. Atmospheric $\mathrm{CO}_{2}$ consumption by continental erosion: present-day controls and implications for the last glacial maximum." Global and Planetary Change, 6, pp. 107-120.

Liu, Z. and Zhao, J., 2000. Contribution of carbonate rock weathering to the atmospheric $\mathrm{CO}_{2}$ sink. Environmental Geology, 39(9), pp. 1053-1058.

Gombert, P., 2002. Role of karstic dissolution in global carbon cycle. Global and Planetary Change, 33(1), pp. 177-184.

Tao, X.D., 2013. Research of karst carbon sink based on RS technology-Case of Guangxi area. Guilin University of Technology.

Zhou, G. Q., Jia, B., et al., 2017. Carbon sink estimation of surface carbonate karstification in global karst area. 2017 IEEE International Geoscience and Remote Sensing Symposium.

Plummer, L. N., Wigley, T. M. L. and Parkhurst, D. L., 1978. The kinetics of calcite dissolution in $\mathrm{CO}_{2}$-water systems at 5 degrees to 60 degrees $\mathrm{C}$ and 0.0 to $1.0 \mathrm{~atm} \mathrm{CO}_{2}$. American Journal of Science, 278(2), pp. 179-216.

Dreybrodt, W. and Dieter, B., 1991. A mass transfer model for dissolution and precipitation of calcite from solutions in turbulent motion. Chemical Geology, 90(1-2), pp. 107-122.

Liu, Z.H., 2000. Contribution of carbonate karstification to atmospheric $\mathrm{CO}_{2}$ deposition. China Karst, 19(4), pp. 293-300.
Amiotte, S. and Probst, J. L., 1995. A global model for presentday atmospheric/soil $\mathrm{CO}_{2}$ consumption by chemical erosion of continental rocks $\left(\mathrm{GEM}-\mathrm{CO}_{2}\right)$.Tellus, 47B, pp. 273-280.

Pacheco, F. and Weijden, C. H., 1996. Contributions of WaterRock Interactions to the Composition of Groundwater in Areas with a Sizeable Anthropogenic Input: A Case Study of the Waters of the Fundão Area, Central Portugal. Water Resources Research, 32(12), pp. 3553-3570.

Ludwig, W., Amiotte-Suchet, P., Munhoven, G., et al., 1998. Atmospheric $\mathrm{CO}_{2}$, consumption by continental erosion: presentday controls and implications for the last glacial maximum. Global \& Planetary Change, 403(s1-2), pp. 107-120.

Roy, S., Gaillardet, J. and Allègre, C. J., 1999. Geochemistry of dissolved and suspended loads of the Seine River, France: anthropogenic impact, carbonate and silicate weathering. Geochimica Et Cosmochimica Acta, 63(9), pp. 1277-1292.

Mortatti, J. and Probst, J. L., 2003. Silicate rock weathering and atmospheric/soil $\mathrm{CO}_{2}$, uptake in the Amazon basin estimated from river water geochemistry: seasonal and spatial variations. Chemical Geology, 197(1-4), pp. 177-196.

Wu. W., Xu, S., Yang, J., et al., 2008. Silicate weathering and $\mathrm{CO}_{2}$, consumption deduced from the seven Chinese rivers originating in the Qinghai-Tibet Plateau. Chemical Geology, 249(3-4), pp. 307-320. 